\title{
Can Oil Prices Predict Japanese Yen?
}

\author{
Neluka Devpura ${ }^{1}$ a \\ ${ }^{1}$ Department of Statistics, Faculty of Applied Sciences, University of Sri Jayewardenepura, Sri Lanka \\ Keywords: exchange rate, predictability, time-varying, japanese yen, oil price \\ 10.46557/001c.17964
}

\section{Asian Economics Letters}

In this paper, we examine the relationship between Japanese Yen (vis-à-vis the US dollar)

and the crude oil futures price. The novelty is that we use high frequency (intraday hourly) data to examine time-varying predictability. We find limited evidence that oil prices predict the Yen. There is no time-varying predictability relationship.

\section{Introduction}

The literature has shown the relevance of exchange rates for asset prices, particularly during the COVID-19 period. $\mathrm{P}$. K. Narayan et al. (2020), for instance, show that the Yen exchange rate predicts Japanese stock returns. P. K. Narayan (2020a) show that the Yen has become more resilient to shocks during the COVID-19 period. P. K. Narayan (2020b) shows that bubble activity in the Yen exchange rate has intensified in the COVID-19 period, rendering the market more inefficient. Moreover, Iyke (2020) shows that COVID-19 virus cases predict exchange rates. Over the COVID-19 period, oil prices have become over $900 \%$ more volatile (see Devpura \& Narayan, 2020). Given this literature, we argue that oil price is also a shock to exchange rates given that oil prices have been shown to influence exchange rates and there are multiple theories that support such a relationship, such as the terms of trade channel (see Amano \& Van Norden, 1998) and the wealth channel (see Krugman, 1983); for a survey of relevant theories, see Beckmann et al. (2020). For empirical studies on oil price shocks and exchange rates, see, inter alia, Jiang et al. (2020), Nusair \& Olson (2019), and Jung et al. (2020). ${ }^{1}$

In this paper, we examine whether the West Texas Intermediate (WTI) 1-month oil futures price predicts Japanese Yen. Our hypothesis is that the predictability relationship -that is, the ability of oil prices to predict exchange rates would have become stronger in the COVID-19 period because the Yen has become: (a) more resilient to shocks as demonstrated in the work of P. K. Narayan (2020a); and (b) has seen bubble activity intensify (P. K. Narayan, 2020b). For this reason, given the evolving literature on the Japanese market, in this study we focus on Japan. For the Japanese Yen, we choose the U.S. (United States) dollar as a basis because the WTI oil futures price is expressed in U.S. dollars. Our choice of WTI 1-month oil futures price is mainly because futures are used as a derivative contract to hedge against any risk or uncertainty.

Our approach to testing the proposed hypothesis is to employ a time-varying predictability model. That our dataset is high frequency aids our approach and hypothesis test. Hourly data span 17 hours per day and cover the period $01 / 07 / 2019$ to $04 / 09 / 2020$. Our in-sample predictability setup is based on using the first $50 \%$ of the sample as the first estimation window and continue recursive estimation by expanding the window by an hour thereafter until the sample is exhausted. In order to depict any predictability relationship emanating from COVID-19, we divide the main sample into two sub-samples, namely, a pre-COVID-19 period (01/07/2019 to 30/12/2019) and a COVID-19 sub-sample (from $31 / 12 / 2019$ to $04 / 09 / 2020){ }^{2}$

The main findings are; first, the oil price has predictive ability for Japanese Yen but the evidence is limited. Our results indicate that, for the full sample, the oil price predicts Yen only about $6 \%$ of the time. Hence, we do not find evidence that Yen predictability is time-varying. Second, with regards to the direction of the relationship, we discover the negative relationship is dominant overall, particularly during the COVID-19 sample. We evaluate the sensitivity of our results to the in-sample window choice by setting it to $25 \%$ of the data. We obtain consistent results regarding the direction of the negative relationship.

This paper contributes to the literature in the following way. Post-COVID-19, the Japanese Yen has received most attention from an exchange rate evolution and behavior points of view, as reviewed earlier. We add to these studies by showing that the evolution of the Yen in the COVID-19 period has little to do with the oil price, which has traditionally been regarded as a predictor of exchange rates.

The research paper is organized as follows. Section II explains our data and methodology. Section III presents and discusses results. Finally, we present concluding remarks in Section IV.

\section{Data and Methodology}

We have Japanese Yen against the US dollar as the exchange rate variable $\left(J P Y \_R E T\right)$ and the WTI 1-month oil

\footnotetext{
a Corresponding author: Department of Statistics, Faculty of Applied Sciences, University of Sri Jayewardenepura, Sri Lanka. Email: ndevpura@sci.sjp.ac.lk

1 For oil price and exchange rate relationship, see Basher et al. (2012, 2016); for U.S. dollar and oil relationship, see F. Wen et al. (2018) and D. Wen et al. (2020); for oil price and Indonesia's exchange rate, see S. Narayan et al. (2019); and for oil price and Fiji's exchange rate, see P. K. Narayan et al. (2008). Moreover, Liu et al. (2020) examine whether oil price predicts exchange rates.

2 For Japanese currency and stock market relationship, see P. K. Narayan et al. (2020) study using daily data with the COVID-19 period to pre-COVID-19 period.
} 


\begin{tabular}{|c|c|c|c|c|c|c|}
\hline & \multicolumn{2}{|c|}{$\begin{array}{l}\text { Panel A: } \\
\text { Full Sample }\end{array}$} & \multicolumn{2}{|c|}{$\begin{array}{c}\text { Panel B: } \\
\text { Pre-COVID-19 Sub-sample }\end{array}$} & \multicolumn{2}{|c|}{$\begin{array}{c}\text { Panel C: } \\
\text { COVID-19 Sub-sample }\end{array}$} \\
\hline & $J P Y$ & oil & $J P Y$ & oil & $J P Y$ & oil \\
\hline Mean & 107.84 & 46.35 & 108.00 & 56.69 & 107.72 & 38.77 \\
\hline Median & 107.81 & 52.44 & 108.26 & 56.51 & 107.50 & 40.33 \\
\hline Maximum & 112.15 & 64.57 & 109.78 & 62.71 & 112.15 & 64.57 \\
\hline Minimum & 102.06 & -7.65 & 105.12 & 50.60 & 102.06 & -7.65 \\
\hline Std. Dev. & 1.42 & 13.13 & 1.10 & 2.33 & 1.61 & 12.61 \\
\hline Skewness & -0.13 & -0.91 & -0.67 & 0.21 & 0.12 & -0.23 \\
\hline Jarque-Bera & 32.83 & 725.73 & 191.16 & 38.42 & 8.64 & 36.23 \\
\hline Probability & 0.00 & 0.00 & 0.00 & 0.00 & 0.01 & 0.00 \\
\hline \multirow[t]{3}{*}{ Observations } & 5270 & 5270 & 2227 & 2227 & 3043 & 3043 \\
\hline & \multicolumn{3}{|c|}{ Panel D: Japanese Yen Log Percentage Return } & & & \\
\hline & Pre-COVID & COVID & & & & \\
\hline Mean & 0.000 & -0.001 & & & & \\
\hline Median & 0.000 & 0.000 & & & & \\
\hline Maximum & 1.266 & 1.090 & & & & \\
\hline Minimum & -0.672 & -3.111 & & & & \\
\hline Std. Dev. & 0.085 & 0.135 & & & & \\
\hline Skewness & 1.005 & -4.054 & & & & \\
\hline Jarque-Bera & 86666 & 1249034 & & & & \\
\hline Probability & 0.00 & 0.00 & & & & \\
\hline Observations & 2226 & 3042 & & & & \\
\hline
\end{tabular}

This table reports descriptive statistics of the Japanese Yen (against the U.S. dollar) and the WTI 1-month oil futures price. Panel A shows the results for the full sample period from 01/07/2019 to 04/09/2020, Panel B indicates the pre-COVID-19 sub-sample from 1/07/2019 to 30/12/2019 and Panel C shows the COVID-19 sub-sample from 31/12/2019 to 04/09/ 2020. The Panel D presents descriptive statistics for the Japanese Yen log percentage returns for both the pre-COVID-19 and the COVID-19 sub-samples.

futures price as a proxy for oil price (oil). The data are 17-hour per day, from 01:00am to 17:00pm. The time frame is from $01 / 07 / 2019$ to $04 / 09 / 2020$. The data include the COVID-19 period: we divide the main sample into two subsamples, namely the pre-COVID-19 period (01/07/2019 to $30 / 12 / 2019)$ and the COVID-19 sub-sample period (31/12/ 2019 to $04 / 09 / 2020)$.

We calculate the natural log percentage returns of the Yen as:

$$
J P Y_{-} R E T=\left(\ln \left(J P Y_{t}\right)-\ln \left(J P Y_{t-1}\right)\right) * 100
$$

We employ the Westerlund and Narayan (2012, 2015) predictive regression model that examines the null hypothesis of no predictability, $H_{0}: \beta=0$, as follows:

$J P Y \_R E T_{t}=\alpha+\beta$ oil $_{t-1}+\gamma\left(\right.$ oil $_{t}-$ oil $\left._{t-1}\right)+\varepsilon_{t}$

In this regression, we include $\left(o i l_{t}-o i l_{t-1}\right)$ in order to control for persistency and endogeneity of the oil variable, and $\varepsilon_{t}$ is the disturbance term. In order to control for heteroskedasticity, we divide each variable by its corresponding standard deviation. Finally, the coefficients are estimated using the Ordinary Least Squares method.

\section{Discussion of Results}

In this section, we elaborate on the descriptive statistics followed by the time-varying results from Equation (2).

Table 1 (Panel A) shows the descriptive statistics for the full sample of data while Panels $B$ and $C$ show statistics for the pre-COVID-19 and the COVID-19 sub-samples, respec- tively. The average of Japanese Yen is roughly the same for the full sample and the two sub-samples. When we consider the standard deviation, we see the lowest is reported for the pre-COVID-19 sample (JPY 1.10). The skewness measure is negative in both the full sample and the pre-COVID sample; however, in the COVID-19 sample it is positive, indicating possible asymmetry. The Jarque-Bera test rejects the null hypothesis of normality for all samples in the case of the Yen. Regarding evidence from oil price data, the average is lowest in the COVID-19 sample. The standard deviation is highest in the full sample. However, when we split the data into sub-samples, the standard deviation is higher in the COVID-19 sample. This indicates that the higher volatility in the full sample is mainly coming from the COVID-19 period. For oil price, the null of normality is rejected for all samples. Finally, Panel D reports the descriptive measures for the log percentage returns of the Yen. The average is negative and volatility is higher in the COVID-19 sample compared to the pre-COVID-19 period.

Our objective is to examine the time-varying relationship between the Yen and the oil price. Figure 1 illustrates the results from Equation (2). The recursive coefficients of the oil price variable are presented in Panel A. We have a horizontal line across 0 to differentiate the positive and negative values. We notice that the direction of the relationship is unstable. However, from mid-March 2020 the sign is negative throughout. The corresponding $t$-statistics of the oil price coefficients are plotted in Panel B. The horizontal line at \pm 1.96 indicates the standard normal distribu- 
Panel A

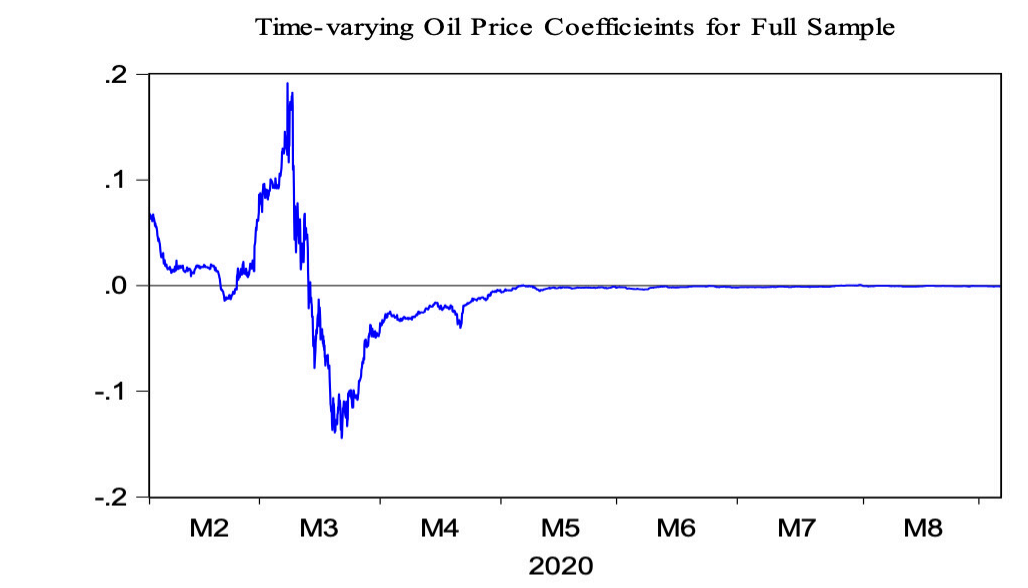

Panel B

Time-varying t-statisics for Full Sample

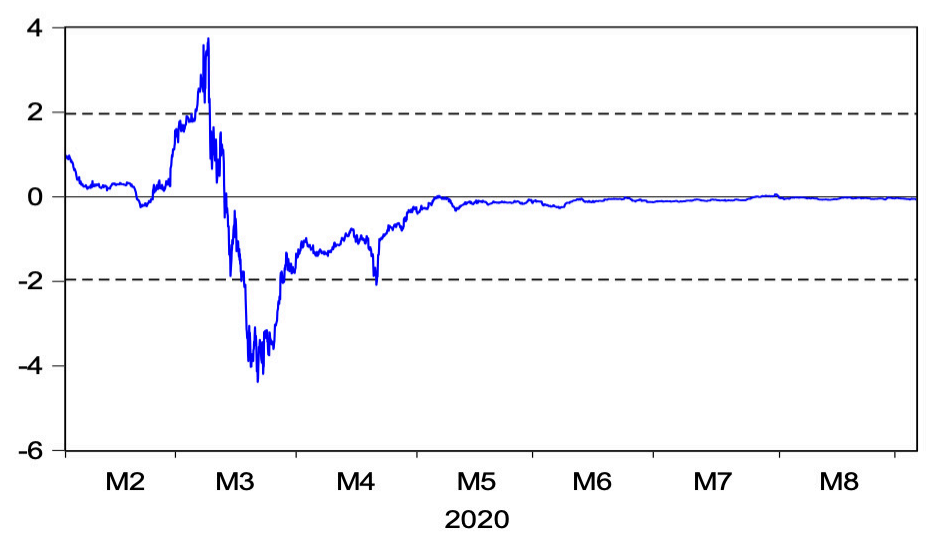

Figure 1: Time-Varying Oil Coefficients -Full sample (01/07/2019 to 04/09/2020)

This figure illustrates the regression results from the model, $J P Y_{-} R E T_{t}=\alpha+\beta o i l_{t-1}+\gamma\left(o i l_{t}-o i l_{t-1}\right)+\varepsilon_{t}$. Here, $J P Y_{-} R E T_{t}$ is the Japanese Yen in natural log percentage return form, $o i l_{t}$ is the WTI 1-month oil futures price, and $\varepsilon_{t}$ is the disturbance term. We use a recursive window to estimate time-varying $\beta$ coefficients. The first $50 \%$ of the data are used as an in-sample period and the model is estimated. We then increase the sample by one observation (by one-hour) and generate the second estimated $\widehat{\beta}$. We use this process until the last observation of the data is completed. Panel A indicates $\widehat{\beta}$ estimated from the model against time and Panel B shows the corresponding $t$-statistics against time. The horizontal line at \pm 1.96 is to identify the significance of the $\widehat{\beta}$ at $5 \%$ significance level.

tion values at the $5 \%$ level of significance. If the coefficients lie beyond these limits, then the relationship can be considered as statistically significant. We notice that only in the month of March 2020 oil prices predict Yen.

In Figure 2, for the pre-COVID-19 period (Panel A), the $t$ -statistics range from 0 to 1.2 and show a positive relationship throughout the pre-COVID-19 period. However, the $t$ -statistics for the COVID-19 sample (Panel B) are dominated by negative values. Overall, we do not find evidence that oil prices predict the Yen when using a $50 \%$ recursive timevarying approach.

For robustness, we re-estimated Equation (2) by using $25 \%$ of the initial data as in-sample and the process is continued until all the data are used. The results are not shown here due to space constraints but are available upon request. We find that the results are consistent with those obtained when using a 50\% in-sample window. Again, the only period when oil prices predict the Yen is in March 2020.

\section{Conclusion}

We examine the relationship between the Japanese Yen (vis-à-vis the US dollar) and the WTI 1-month oil futures price using hourly data (01/07/2019 to 04/09/2020). Our main contribution is that we test the predictability rela- tionship using a time-varying model. Based on $50 \%$ of data in-sample, we find that in only about $6 \%$ of the sample oil prices predict the Yen. This relationship only exists in March 2020. Post-March 2020, there is no evidence of any predictability. Our main conclusion, therefore, is that oil prices and the Yen do not share a time-varying predictability relationship.

Submitted: October 30, 2020 AEDT, Accepted: November 13, 2020 AEDT 
Panel A

Time-varying Oil Price t-statistics (Pre-COVID-19)

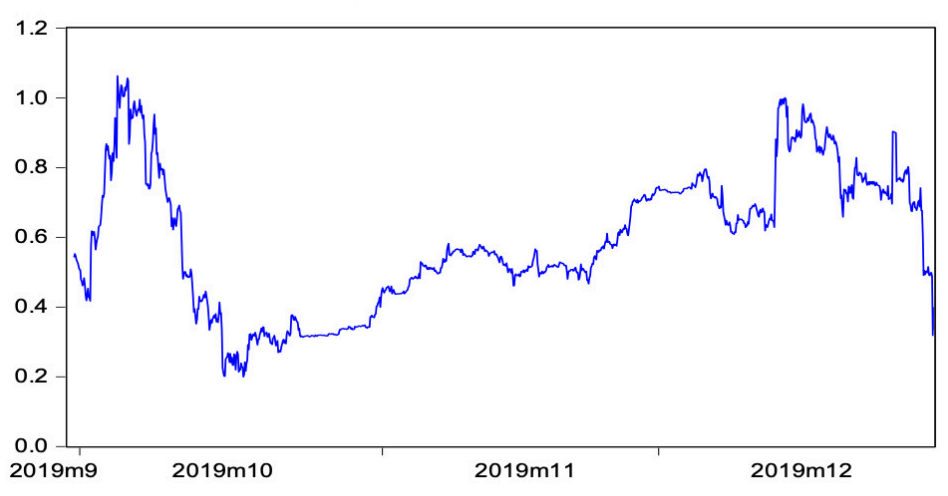

Panel B

Time-varying t-statistics for Oil Price (COVID-19 Sub-sample)

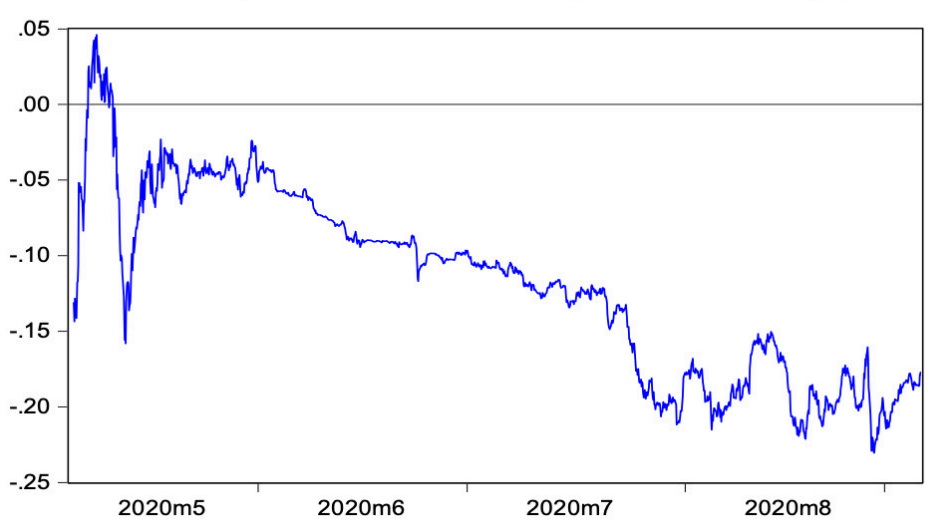

\section{Figure 2: Time-varying t-statistics for sub-sample}

This figure illustrates the regression results from the model, $J P Y_{-} R E T_{t}=\alpha+\beta$ oi $l_{t-1}+\gamma\left(o i l_{t}-o i l_{t-1}\right)+\varepsilon_{t}$. Here, $J P Y_{-} R E T_{t}$ is the Japanese Yen in natural log percentage return form, oil $l_{t}$ is the WTI 1-month oil futures price, and $\varepsilon_{t}$ is the disturbance term. We use a recursive window to estimate time-varying $\beta$ coefficients. The first $50 \%$ of the data are used as an in-sample period and the model is estimated. We then increase the sample by one observation (by one-hour) and generate the second estimated $\widehat{\beta}$. We use this process until the last observation of the data is used. Panel A indicates $t$-statistics against time for the pre-COVID-19 sample (01/07/2019 to 30/12/2019) and Panel B shows the $t$-statistics against time for the COVID-19 sample (31/12/2019 to 04/09/2020) respectively.

This is an open-access article distributed under the terms of the Creative Commons Attribution 4.0 International License (CCBY-SA-4.0). View this license's legal deed at https://creativecommons.org/licenses/by-sa/4.0 and legal code at https://creativecommons.org/licenses/by-sa/4.0/legalcode for more information. 


\section{REFERENCES}

Amano, R. A., \& Van Norden, S. (1998). Exchange rates and oil prices. Review of International Economics, 6(4), 683-694. https://doi.org/10.1111/14 $\underline{67-9396.00136}$

Basher, S. A., Haug, A. A., \& Sadorsky, P. (2012). Oil prices, exchange rates and emerging stock markets. Energy Economics, 34(1), 227-240. https://doi.org/1 0.1016/j.eneco.2011.10.005

Basher, S. A., Haug, A. A., \& Sadorsky, P. (2016). The impact of oil shocks on exchange rates: A Markovswitching approach. Energy Economics, 54, 11-23. ht tps://doi.org/10.1016/j.eneco.2015.12.004

Beckmann, J., Czudaj, R. L., \& Arora, V. (2020). The relationship between oil prices and exchange rates: Revisiting theory and evidence. Energy Economics, 88, 104772. https://doi.org/10.1016/j.eneco.2020.1047 $\underline{72}$

Devpura, N., \& Narayan, P. K. (2020). Hourly oil price volatility: The role of COVID-19. Energy Research Letters, 1(2). https://doi.org/10.46557/001c.13683

Iyke, B. N. (2020). The Disease Outbreak Channel of Exchange Rate Return Predictability: Evidence from COVID-19. Emerging Markets Finance and Trade, 56(10), 2277-2297. https://doi.org/10.1080/1540496 $\underline{\mathrm{x} .2020 .1784718}$

Jiang, Y., Feng, Q., Mo, B., \& Nie, H. (2020). Visiting the effects of oil price shocks on exchange rates: Quantile-on-quantile and causality-in-quantiles approaches. The North American Journal of Economics and Finance, 52, 101161. https://doi.org/1 0.1016/j.najef.2020.101161

Jung, Y. C., Dam, A., \& McFarlane, A. (2020). The asymmetric relationship between the oil price and the US-Canada exchange rate. The Quarterly Review of Economics and Finance, 76, 198-206. https://doi.org/ 10.1016/i.qref.2019.06.003

Krugman, P. (1983). .Oil Shocks and Exchange Rate Dynamics. , Exchange Rates and International Macroeconomics, National Bureau of Economic Research, Inc, 259-284. https://EconPapers.repec.or g/RePEc:nbr:nberch:11382
Liu, L., Tan, S., \& Wang, Y. (2020). Can commodity prices forecast exchange rates? Energy Economics, 87, 104719. https://doi.org/10.1016/j.eneco.2020.104719

Narayan, P. K. (2020a). Has COVID-19 Changed Exchange Rate Resistance to Shocks? Asian Economics Letters, 1(1). https://doi.org/10.46557/001 c.17389

Narayan, P. K. (2020b). Did Bubble Activity Intensify During COVID-19? Asian Economics Letters, 1-5. htt ps://doi.org/10.46557/001c.17654

Narayan, P. K., Devpura, N., \& Wang, H. (2020). Japanese currency and stock market-What happened during the COVID-19 pandemic? Economic Analysis and Policy, 68, 191-198. https://doi.org/10.1016/j.ea p.2020.09.014

Narayan, P. K., Narayan, S., \& Prasad, A. (2008). Understanding the oil price-exchange rate nexus for the Fiji islands. Energy Economics, 30(5), 2686-2696. https://doi.org/10.1016/j.eneco.2008.03.003

Narayan, S., Falianty, T., \& Tobing, L. (2019). The influence if oil prices in Indonesia's exchange rate. Bulletin of Monetary Economics and Banking, 21(3), 303-322. https://doi.org/10.21098/bemp.v21i3.1007

Nusair, S. A., \& Olson, D. (2019). The effects of oil price shocks on Asian exchange rates: Evidence from quantile regression analysis. Energy Economics, Elsevier, 78, 44-63.

Wen, D., Liu, L., Ma, C., \& Wang, Y. (2020). Extreme Risk Spillovers Between Crude Oil Prices and the U.S. Exchange Rate Evidence from Oil-exporting and Oilimporting countries. Energy, 212, 1-16.

Wen, F., Xiao, J., Huang, C., \& Xia, X. (2018). Interaction between oil and US dollar exchange rate: Nonlinear causality, time-varying influence and structural breaks in volatility. Applied Economics, 50(3), 319-334. https://doi.org/10.1080/00036846.201 7.1321838 